\title{
artigo
}

Armada e Silva, H.C.D.; Bernardo da Silva, M.R.; Carvalho, S.S.S.; Cunha, A.L.; Souza, D.R.S.; Bernardo da Silva, R.;

Influência dos responsáveis de adolescentes no impacto à adesão da vacina HPV

\section{Influência dos responsáveis de adolescentes no impacto à adesão da vacina HPV}

The influence of adolescents responsible on the impact of HPV vaccine adhesion

Influencia de los adolescentes responsables del impacto de la adhesión de vacunas del VPH

\section{RESUMO}

Objetivo: Analisar o papel dos responsáveis frente à vacinação do HPV, identificando fatores que influenciam a adesão vacinal dos adolescentes Método: Pesquisa qualitativa, descritiva, com a utilização do método de análise de conteúdo de Bardin, após aprovação do comitê ética 3.098.551 de acordo com a Resolução 580/18. Resultados: A aplicação da análise de conteúdo gerou três categorias: "O nível de informação dos responsáveis a respeito da vacina HPV", "O vínculo da equipe ESF com a família representada pelo responsável presente" e "O nível da articulação do enfermeiro no processo de promoção em saúde. Conclusão: Pode-se observar que há por parte dos familiares um vínculo estabelecido com a equipe da ESF e que a maior parte dos responsáveis de adolescentes vacinados contra o vírus do HPV tem informações sobre a doença, consequências da não vacinação e seus benefícios. DESCRITORES: Prevenção; Relação Familiar; Neoplasias do Colo do Útero.

\section{ABSTRACT}

Objective: To analyze the role of those responsible for HPV vaccination, identifying factors that influence the vaccination adherence of adolescents Method: Qualitative, descriptive research, using the method of content analysis by Bardin after approval by the Ethical Committee 3.098.551 according to Resolution 580/18. Results: the application of the content analysis generated three categories: "The level of information of those responsible for the HPV vaccine", "The link of the FHS team with the family represented by the person in charge" and "The level of the nurse's articulation in the process health promotion. Conclusion: It can be observed that there is a relationship between the family members and the FHS team, and that most parents of adolescents vaccinated against the HPV virus have information about the disease, consequences of non-vaccination and its benefits.

DESCRIPTORS: Prevention; Family Relationship; Cervical Neoplasms.

\section{RESUMEN}

Objetivo: analizar el papel de los responsables de la vacunación contra el VPH, identificar los factores que influyen en la adherencia a la vacunación de adolescentes. Método: Investigación cualitativa, descriptiva, utilizando el método de análisis de contenido de Bardin después de la aprobación del Comité Ético 3.098.551 según la Resolución 580/18. Resultados: La aplicación del análisis de contenido generó tres categorías: "El nivel de información de los responsables de la vacuna contra el VPH", "El vínculo entre el equipo de FHS y la familia representada por la persona responsable" y "El nivel de articulación de la enfermera en el proceso promoción de la salud. Conclusión: Podemos observar que existe una relación entre los miembros de la familia y el equipo de FHS y que la mayoría de los padres de adolescentes vacunados contra el virus del VPH tienen información sobre la enfermedad, las consecuencias de la no vacunación y sus beneficios.

DESCRIPTORES: Prevención; Relación Familiar; Neoplasias Cervicales.

RECEBIDO EM: 17/12/2019 APROVADO EM: 19/12/2019

\section{Halene Cristina Dias Armada e Silva}

Doutoranda da UERJ. Mestre em Enfermagem. Coordenadora da Coordenação de AP 5.2 RJ. ORCID: https://orcid.org/00000001-7427-781X

\section{Maria Regina Bernardo da Silva}

Mestre em Saúde da Família e Comunidade. MBA em gestão em Saúde. Docente da Universidade Castelo Branco e UNIBCE/RJ. ORCID: https://orcid.org/0000-0002-3620-3091

\section{Suzele Soares da Silva de Carvalho}

Enfermeira da Estratégia Saúde da Família. Pós-Graduanda em ESF na Universidade Castelo Branco. ORCID: https://orcid. org/0000-0003-0158-6878 


\section{Adriana Loureiro da Cunha}

Doutoranda da UERJ. Docente da Universidade Castelo Branco. ORCID: https://orcid.org/0000-0002-6971-4357

\section{Daniel Ribeiro Soares de Souza}

Mestre em Saúde e Tecnologia. Docente da Universidade Castelo Branco e Uni São José. ORCID: https://orcid.org/0000-00029170-6193

\section{Raquel Bernardo da Silva}

Mestranda em Atenção Primária na UFRJ. Preceptora de Residência em Enfermagem PRESF. ORCID: https://orcid.org/00000001-8791-2720

\section{INTRODUÇÃO}

A motivação da pesquisa surgiu durante atuação em um Centro Municipal de Saúde no Rio de Janeiro, onde se observou o quanto o grau de informação dos responsáveis concernente à vacina HPV influenciava na adesão do adolescente ao esquema vacinal.

A vacinação é um dos meios mais eficazes na defesa do organismo humano contra agentes infecciosos, sendo uma das estratégias de prevenção contra algumas ISTs.

Infecções Sexualmente Transmissíveis (IST) compõem o conjunto de infecções distintas que têm a intertextualidade de serem transmitidas pelo contato sexual, sendo reconhecidas como um importante problema de saúde pública em todo o mundo, com maior visibilidade a partir da década de 1980, quando surgiram os primeiros casos de AIDS ${ }^{(1)}$. Dentre as ISTs, está o papilomavírus humano.

O papilomavírus humano (HPV) é um vírus da família Papilomaviridae capaz de provocar lesões de pele ou mucosa. São mais de 100 tipos, porém, estudos revelam que somente 20 infectam o trato genital, sendo seu período de incubação de um a vinte meses, com média de três meses ${ }^{(2)}$.

Quando no organismo humano, o HPV pode provocar doença que frequentemente manifesta-se como infecção nos genitais, tanto em homens como mulheres, provocando lesões múltiplas, localizadas ou difusas e de tamanho variável. A localização dessas lesões em homens ocorre nas regiões do pênis, sulco bálano-prepucial, região perianal. Nas mulheres, ocorrem na vulva, períneo, vagina e colo do útero. Essas lesões são caracterizadas por verruga/condiloma genital vulgarmente conhecida como "crista de galo"(3).

Em 2014, o Ministério da Saúde incluiu no calendário vacinal do Sistema Único de Saúde (SUS) a vacina quadrivalente papilomavírus humano 6, 11, 16, 18 (recombinante). Através da tecnologia recombinante, a vacina quadrivalente é produzida a partir de proteínas estruturais L1 purificadas, que não trazem riscos à saúde. Essas proteínas produzem um tipo específico de HPV que não contem produtos vivos ou DNA viral, sendo, portanto, não infecciosa ${ }^{(4)}$.

Os adolescentes constituem uma população de alta vulnerabilidade para o agravo de câncer de colo do Útero (CCU), também conhecido como cervical, na medida em que o início precoce da vida sexual e multiplicidade de parceiros de forma desprevenida e irresponsável os aproximam de problemas de saúde da esfera reprodutiva e sexual(5). O contágio pelo HPV, principal agente oncogênico do câncer de colo uterino, ocorre no início da vida sexual na adolescência ou por volta dos $20 \operatorname{anos}^{(6)}$.

Um dos maiores influenciadores na aceitação de prevenção ofertadas pelo Ministério da Saúde ainda é o grupo familiar, no qual é a primeira e mais importante influência na vida das pessoas. É nele que adquirimos os valores, os usos e os costumes que irão formar nossa personalidade e bagagem emocional. Podemos caracterizá-lo por um grupo de pessoas com vínculos afetivos, de consanguinidade e de convivência ${ }^{(7)}$.

Sendo assim, o objeto do estudo é a influência dos responsáveis no impacto à adesão de adolescentes à vacina do HPV e a pergunta de pesquisa: Qual o papel dos responsáveis de adolescentes frente à vacinação HPV? Tendo como objetivo geral analisar o papel dos responsáveis dos adolescentes frente à vacinação e, objetivos específicos: identificarem fatores que influenciam a adesão dos adolescentes à vacina $\mathrm{HPV}$ e discutir a participação do enfermeiro na articulação educativa aos pais e adolescentes na adesão vacinal.

\section{METODOLOGIA}

Trata-se de uma pesquisa qualitativa, quantitativa e descritiva a qual objetivou conhecer a influência dos responsáveis na adesão dos adolescentes à vacina do HPV. O estudo foi realizado em um Centro Municipal de Saúde (CMS) localizado no bairro de Vila Kennedy, Zona Oeste do Município do Rio de Janeiro, Coordenadoria Geral Área Programática 5.1. A escolha do território se deu por conhecimento de um perfil epidemiológico vacinal insatisfatório no que se refere à adesão à vacina do HPV. A área programática da equipe destacada é composta por 1025 famílias e 2.772 usuários cadastrados até o momento da pesquisa, tendo como característica ser uma área de alto índice de periculosidade e vulnerabilidade.

Os participantes foram os responsáveis legais dos adolescentes de ambos os sexos na faixa etária de 9 a 14 anos de 
idade. O Termo de Consentimento Livre e Esclarecido (TCLE) foi assinado por aqueles que participaram das entrevistas. Os participantes foram identificados por números, exemplo: $1,2,3,4 \ldots$ a fim de garantir o anonimato.

Os critérios de inclusão foram responsáveis legais de adolescente do sexo feminino da faixa etária de 9 a 14 anos de idade e responsáveis legais de adolescentes do sexo masculino da faixa etária de 11 a 14 anos de idade. A amostra foi composta por responsáveis cadastrados através do prontuário eletrônico Vitacare de uma equipe responsável por cinco microáreas da Estratégia Saúde da Família (ESF).

A coleta foi realizada mediante questionário semiestruturado contendo 06 questões objetivas que, antecipadamente, fora esclarecido pela pesquisadora quanto ao preenchimento do mesmo e aplicado de forma individual nos meses de setembro e outubro 2018 de acordo com as disponibilidades de horário dos responsáveis, mas foram feitos em três grupos. Antes do início de cada grupo, foi feita a leitura do TCLE. A entrevista foi baseada em um roteiro de perguntas, testado previamente, que também foi apresentado para aprovação da Comissão de Ética. O roteiro foi composto de perguntas fechadas e abertas aos usuários que aceitaram participar.

Logo após, foi desenvolvida uma roda de conversa com auxílio de slides com objetivo de ouvir experiências, informar e orientar os responsáveis quanto aos benefícios e importância da adesão à vacina HPV, onde foi observado como os responsáveis apresentavam adesão e conhecimento sobre a vacina $H P V$.

Para a análise dos resultados, empregamos o método de análise de conteú$\mathrm{do}^{(8)}$, um dos trabalhos mais referidos em estudos qualitativos que sugere a utilização da análise de conteúdo prevê três fases fundamentais: pré-análise, exploração do material e tratamento dos resultados - a inferência e a interpretação.
Logo após, foi

desenvolvida

uma roda de

conversa com

auxílio de slides

com objetivo de

ouvir experiências,

informar e orientar

os responsáveis

quanto aos

benefícios e

importância da

adesão à vacina

HPV, onde foi

observado como

os responsáveis

apresentavam

adesão e

conhecimento sobre

a vacina $H P V$.
A seguir, foram selecionadas desse material as ideias mais importantes e relevantes buscando os dados necessários para o alcance dos objetivos da pesquisa, mediante as observações feitas durante os grupos e entrevistas individuais, os dados obtidos se desdobraram em núcleos ou unidades que foram apresentados por categorias ${ }^{(9)}$.

A pesquisa passou pelo Comitê de Ética em Pesquisa de acordo com a Resolução n. ${ }^{\circ} 580 / 18$ sob o parecer n. ${ }^{\circ}$ 3.098.551. O material coletado foi de uso exclusivo do pesquisador, sendo utilizado com a única finalidade de fornecer elementos para a realização deste projeto de pesquisa, da própria pesquisa e dos artigos e publicaçóes que dela resultem.

$\mathrm{Na}$ pesquisa, foi assegurada a confidencialidade da identidade dos participantes. O material coletado não será objeto de comercialização ou divulgação que possa prejudicar os entrevistados. Mas será feito artigo para publicação.

\section{RESULTADOS E DISCUSSÃO}

Havia 42 responsáveis de adolescentes de 09 a 14 anos como participantes do estudo e, no decorrer da pesquisa, houve uma desistência, restando 41 participantes.

Foi analisado o conhecimento dos responsáveis a respeito da imunização da vacina contra o HPV, no qual $27 \%$ dos participantes se mostraram bem informados, $22 \%$ com conhecimento parcial e $51 \%$ sem nenhum tipo de conhecimento do assunto citado, ficando clara a deficiência de informação sobre os benefícios da vacina citada. A resposta que mais prevaleceu entre os responsáveis foi que a vacina destacada previne contra câncer no colo do útero e contra as ISTs. Contudo, na roda de conversa educativa ministrada, foi relatado para os presentes que a mesma só imuniza contra o vírus HPV, principal responsável não somente pelo câncer do colo do útero, mas também 
câncer de pênis e câncer no ânus. O resultado exposto deixa clara a falta de progresso na abordagem a população sobre o assunto discutido, quando comparado aos resultados ${ }^{(10)}$ que já alertava-se: "Os resultados reforçam a necessidade de haver intervenções educativas na população para prover informação adequada sobre o HPV e medidas de prevenção".

Ao serem abordados a respeito da pessoa de confiança que o adolescente tem liberdade para declarar seus medos, dúvidas sobre a saúde, descobertas físicas e fisiológicas, interesse sexual e sentimental aos olhos dos responsáveis, $54 \%$ declararam serem os mesmos a maior figura de confiança dos adolescentes. Destacou-se também a figura da avó com $27 \%$, tendo como justificativa o motivo de trabalho dos pais e em outros casos, abandono devido ao vício de drogas ilícitas, resultando na ausência dos responsáveis e formação de maior confiança com avó, concordando com estudo ${ }^{(11)}$ que diz que: "O relacionamento avós-netos marcado pelo prazer e brincadeiras ocorre mais na infância, mas à medida que os netos vão crescendo, outros significados vão adquirindo mais relevância, como as características dos próprios avós e seus netos, assim como da relação".

Além de $7 \%$ tendo outros familiares como referência. Além de 12\% confiarem em amigos, sem vínculos familiares.

$\mathrm{Na}$ maioria dos relatos, $66 \%$ dos responsáveis afirmam que os filhos estudam e rede pública e que em algum momento chegam a casa informando citando: [...] 1, 2, 4 "o posto foi lá na escola hoje”, porém $34 \%$ dos responsáveis encontram-se insatisfeita pela ausência da ESF no colégio de atuação do filho devido esta ser uma instituição particular. Isso faz com que diversos cadastrados da área não recebam em sua unidade de ensino a assistência da ESF. Foi apresentado o protocolo a ser praticado no caso e orientado sobre o grupo de ado- lescentes na unidade de referência, ficando clara a importância de a ESF entrar em parceria também com as escolas particulares, uma vez que os usuários estão em atuação nela, além de terem a figura do professor como de grande influência em suas tomadas de decisões relacionadas aos temas abordados em sala de aula.

Foi observado também o conhecimento dos responsáveis e, consequentemente, dos adolescentes quanto à existência do grupo ativo em saúde de adolescentes de 09 a 16 anos que ocorre na unidade de referência quinzenalmente, neste, $98 \%$ apontou para o desconhecimento, até aquele momento, da existência do grupo citado como relatos [...] 3,4,6, nunca soube de grupo e venho sempre ao atendimento à unidade de saúde [...] e $2 \%$ o conhecia, porém não atuavam no grupo. Contudo, na atividade educativa ministrada, foi orientado aos pais quanto a existência dos grupos, datas das reuniões, características e importância de os adolescentes serem acolhidos, a fim de criar um vínculo com a equipe ESF com o objetivo de absorver e praticar orientações sobre temas relacionados à saúde, família e sociedade.

Também foi passada a problemática para a enfermeira responsável pela área dos entrevistados que, por sua vez, se comprometeu quanto à maior atuação na divulgação do grupo em visitas domiciliares e atendimento ambulatorial.

A maior parte dos responsáveis representadas por $76 \%$ dizem ter facilidades em acessar a equipe ESF, inclusive citam os nomes dos médicos, enfermeiras e ACSs, segundo os relatos: [...] 4,5,7, "conheço minha equipe e eles me conhecem e não tenho dificuldades nem a minha família de atendimento na ESF", porém 24\% dos participantes, que representavam seus familiares, afirmaram que mesmo conhecendo a equipe, não se sentem acolhidos e vinculados a mesma e ainda tiveram entrevistados que disseram
[...] 7, 9 "não conheço ninguém da minha equipe da ESF".

Quanto à adesão da vacina contra HPV e se tal adesão teve influência dos responsáveis, 56\% informaram que seus filhos tiveram adesão à vacina, ainda que parte dos tais, até o momento, não tivessem conhecimento sobre a mesma. Já 32\% afirmaram que os menores não aderiram à vacina com consentimento dos responsáveis e dentre os motivos destacou-se a "falta de tempo por parte dos pais devido a afazeres diários", " por ter ainda muito tempo, como por exemplo da adolescente ter nove anos de idade e a faixa etária ser até os dez anos", e ainda por não terem mais o hábito de "olhar o calendário vacinal uma vez que eles já são grandes". Outros $12 \%$ responsáveis não souberam responder devido à perda ou danos a caderneta vacinal. Conforme estudo(12), a barreira inicial para a baixa adesão à vacina anti-HPV é o desconhecimento da população (pais e adolescentes) sobre o vírus HPV, suas consequências, a saúde e forma de imunização.

\section{CONCLUSÃO}

A partir da análise das entrevistas, verificou-se que os responsáveis, incluindo surpreendentemente a imagem da avó, são grandes influenciadores da adesão vacinal dos adolescentes na faixa etária de 09 a 14 anos, principalmente no que diz respeito à vacina HPV, tendo a maioria dos adolescentes em questão os responsáveis como a figura de maior confiabilidade no que tange às descobertas e esclarecimentos de dúvidas relacionadas à saúde.

Quanto aos responsáveis, foi concluído que, embora em sua maioria tivesse presença ativa na unidade de saúde, os mesmos não participavam de grupos na unidade e muitos nem ao menos sabiam da existência de grupos educativos com foco na prevenção que atuam na unidade ESF. Tal participação poderia ser um aliado para se atu- 


\section{artigo}

Armada e Silva, H.C.D.; Bernardo da Silva, M.R.; Carvalho, S.S.S.; Cunha, A.L.; Souza, D.R.S.; Bernardo da Silva, R.;

Influência dos responsáveis de adolescentes no impacto à adesão da vacina HPV

alizarem e sanarem dúvidas dos adolescentes, participando das práticas educativas que ocorrem na unidade, tais como: grupos, palestras, salas de esperas, rodas de conversas e a própria consulta ambulatorial, os quais não se dedicam em apreender o conhecimento oferecido, pois mesmo presentes, focam em problemas de saúde já presentes em detrimento de medidas de prevenção. Tal atitude impede a entrada do saber referente à saúde e, consequentemente, a multiplicação da informação no seio familiar afetando diretamente o adolescente em questão, uma vez que a maioria não tem contato com a equipe ESF em grupos internos da unidade, como também nas unidades de ensino particular, resultando na falta de acolhimento, informação e a não construção de vínculo com a equipe. Conclui-se que a falta de orienta- ção impede o saber; este impede o entendimento, que impede a aceitação e, consequentemente, a adesão.

Observa-se a responsabilidade dessa falta de adesão que não gera somente em torno dos profissionais que atuam na ESF, mas também dos responsáveis e adultos que não se responsabilizam pelo autocuidado no que tange à própria saúde, da família e comunidade, havendo assim uma dependência absurda e, muitas vezes, desnecessária do usuário referente ao profissional, havendo uma necessidade de conscientização do autocuidado, como por exemplo, do profissional ter que realizar busca ativa na residência, solicitar a caderneta vacinal e apontar para o responsável as vacinas em atraso, sendo que em todo o momento a caderneta está em posse da família, contendo data de aplicação da imunização.
Como proposta, verificou-se a necessidade de divulgação do grupo de adolescentes dos materiais educativos do Ministério da Saúde, aperfeiçoando a linguagem e a mídia visual; valorizando o indivíduo receptor da mensagem seja ele o adolescente ou seu responsável; melhorando a comunicação da equipe sobre o grupo, na porta de entrada da unidade; melhorando a comunicação entre os profissionais de saúde dentro e fora da unidade; criando parceria com unidade de ensino da área mesmo sendo unidade particular, evitar linguagem técnico-científica nos materiais, criar uma educação em saúde menos autoritária e mais humanizada e solicitar com maior frequência a presença da equipe Núcleo de Apoio à Saúde da Família nos encontros e em Visitas Domiciliares.

\section{REFERÊNCIAS}

1. Ministério da Saúde, Instituto Nacional de Câncer (BR). Estimativa 2012: incidência de câncer no Brasil [Internet]. Rio de Janeiro: Inca; 2011 [acesso em 20 mai 2018]. Disponível em: http:// bvsms.saude.gov.br/bvs/publicacoes/abc_do_cancer.pdf.

2. Costa LHR, Souza AF. O conhecimento de mulheres sobre HPV e câncer de colo de útero após consulta de enfermagem. Revista Brasileira de Cancerologia [Internet]. 2015 [acesso em 22 mar 2018]; 61(4). Disponível em: https://rbc.inca.gov.br/revista/index.php/revista/article/view/220.

3. Ruas BRB, et al. Estratégia e adesão da vacinação contra HPV no município de Amparo, São Paulo, Brasil. Revista Saúde em Foco [Internet]. 2017 [acesso em 11 fev 2018]; 9. Disponível em: http://www.unifia.edu.br/revista_eletronica/revistas/saude_foco/artigos/ano2017/008_estrategia_vacina\%C3\%A7\%C3\%A3o_hpv.pdf.

4. Panobianco MS, Lima ADF, Oliveira ISB, Gozzo T O. O conhecimento sobre o HPV entre adolescentes estudantes de graduação em enfermagem. Texto \& Contexto Enfermagem [Internet]. 2013 [acesso em 14 ago 2018]; 22(1):201-207. Disponivel em: http://www.redalyc.org/articulo.oa?id=71425827016.

5. Oliveira VS. O conhecimento de adolescentes acerca dos fatores de risco e prevenção do câncer de colo de útero. Vivências: Revista Eletrônica de Extensão do URI [Internet]. 2015 out [acesso em 12 jun 2018]; 11(21):113-120. Disponivel em http:// www.reitoria.uri.br/ vivencias/Numero_021/artigos/pdf/Artigo_13.pdf.

6. Ministério da Saúde, Secretaria de Políticas de Saúde (BR).
Guia Prático do Agente Comunitário de Saúde [Internet]. Brasília (DF): MS, 2009 [acesso em 13 abr 2018]. Disponivel em: http:// bvsms.saude.gov.br/bvs/publicacoes/cd09_05a.pdf.

7. Camara ARH. Análise de conteúdo: da teoria à prática em pesquisas sociais aplicadas as organizações Gerais. Revista Interinstitucional de Psicologia [Internet]. 2013 jul-dez [acesso em 10 set 2018]; 179-191. Disponivel em: http://pepsic.bvsalud. org/pdf/gerais/v6n2/v6n2a03.pdf.

8. Bardin L. Análise de conteúdo. São Paulo: Edições 70; 2011. $229 \mathrm{p}$.

9. Lakatos EM, Marconi M. Fundamentos de Metodologia Científica. São Paulo: Atlas; 2003. 311p.

10. Osis MJD, Duarte GA e Sousa MH. Conhecimento e atitude de usuários do SUS sobre o HPV e as vacinas disponíveis no Brasil. Rev Saúde Pública [Internet]. 2014 feb [acesso em 10 mai 2019];48(1). Disponível em: https://www.scielosp.org/scielo. php?pid=S0034-89102014000100123\&script=sci_arttext.

11. Dias CMSB, Silva MAS. Os avós na perspectiva de jovens universitários. Psicol Estud [Internet]. 2003 [acesso em 10 mai 2019]; 8(n.esp):55-62. Disponivel em: https://www.redalyc.org/ pdf/4038/403838813019.pdf.

12. Abreu MNS, et al. Conhecimento e Percepção sobre o HPV na População com mais de 18 Anos na Cidade de Ipatinga, MG, Brasil. Ciência e Saúde Coletiva [Internet]. 2018 mar [acesso em 06 abr 2019]; 23(3):849-860. Disponivel em: https://www.scielosp. org/scielo.php?pid=S1413-81232018000300849\&script=sci_arttext\&tlng=en. 